\title{
Idiopathic and acquired pedophilia as two distinct disorders: an insight from neuroimaging
}

\author{
Cristina Scarpazza ${ }^{1,2}$ (1) - Livio Finos ${ }^{3} \cdot$ Sarah Genon $^{4} \cdot$ Laura Masiero $^{5}$ - Elena Bortolato ${ }^{5}$ - Camilla Cavaliere ${ }^{5}$. \\ Jessica Pezzaioli ${ }^{5}$. Merylin Monaro ${ }^{1} \cdot$ Nicolò Navarin $^{6}$. Umberto Battaglia ${ }^{7}$ - Pietro Pietrini ${ }^{8}$. Stefano Ferracuti ${ }^{9}$. \\ Giuseppe Sartori $^{1}$ • Andrea S. Camperio Ciani ${ }^{7}$
}

Received: 19 July 2020 / Revised: 21 December 2020 / Accepted: 28 December 2020

(C) The Author(s) 2021

\begin{abstract}
Pedophilia is a disorder of public concern because of its association with child sexual offense and recidivism. Previous neuroimaging studies of potential brain abnormalities underlying pedophilic behavior, either in idiopathic or acquired (i.e., emerging following brain damages) pedophilia, led to inconsistent results. This study sought to explore the neural underpinnings of pedophilic behavior and to determine the extent to which brain alterations may be related to distinct psychopathological features in pedophilia. To this aim, we run a coordinate based meta-analysis on previously published papers reporting whole brain analysis and a lesion network analysis, using brain lesions as seeds in a resting state connectivity analysis. The behavioral profiling approach was applied to link identified regions with the corresponding psychological processes. While no consistent neuroanatomical alterations were identified in idiopathic pedophilia, the current results support that all the lesions causing acquired pedophilia are localized within a shared resting state network that included posterior midlines structures, right inferior temporal gyrus and bilateral orbitofrontal cortex. These regions are associated with action inhibition and social cognition, abilities that are consistently and severely impaired in acquired pedophiles. This study suggests that idiopathic and acquired pedophilia may be two distinct disorders, in line with their distinctive clinical features, including age of onset, reversibility and modus operandi. Understanding the neurobiological underpinnings of pedophilic behavior may contribute to a more comprehensive characterization of these individuals on a clinical ground, a pivotal step forward for the development of more efficient therapeutic rehabilitation strategies.
\end{abstract}

Keywords Idiopathic pedophilia $\cdot$ Acquired pedophilia $\cdot$ Coordinate based meta-analysis $\cdot$ Lesion network analysis $\cdot$ Behavioral profiling $\cdot$ Neuroimaging

\section{Introduction}

Pedophilia is a paraphilic disorder included within the Diagnostic and Statistic Manual of Mental Disorder (fifth

Cristina Scarpazza

cristina.scarpazza@unipd.it; cristina.scarpazza@gmail.com

1 Department of General Psychology University of Padova Via Venezia 8, 25131 Padova, PD, Italy

2 Department of Psychosis Studies, Institute of Psychiatry, Psychology and Neuroscience, King's College London, London, UK

3 Department of Developmental Psychology and Socialisation, University of Padova, Padova, Italy

4 Institute of Neuroscience and Medicine, Brain and Behaviour (INM-7), Research Centre Jülich, Jülich, Germany edition, American Psychiatric Association 2013) idefined as sexual preferences for prepubescent children, coupled with distress caused by the sexual urges and/or child sexual (American Psychiatric Association 2013; Regier et al. 2013).

5 Department of Statistical Sciences, University of Padova, Padova, Italy

6 Department of Mathematics "Tullio Levi-Civita", University of Padova, Padova, Italy

7 Department of Philosophy, Sociology, Education and Applied Psychology, University of Padova, Padova, Italy

8 Molecular Mind Lab, IMT School for Advanced Studies Lucca, Lucca, Italy

9 Department of Human Neurosciences "Sapienza" University of Rome Rome, Italy 
Although pedophiles are relatively rare (prevalence of 3-5\% in the male population (Beech et al. 2016)), they commit a disproportionate amount of crimes and rarely comply with psychological treatments (Hall and Hall 2007). Pedophilia raises high public concern due to its association with child sexual offense and recidivism (Hanson et al. 2003).

Though the multifactorial origin of pedophilia still remains elusive (Mohnke et al. 2014; Tenbergen et al. 2015), recent neuroimaging studies have shown pedophilia to be associated with reduced grey (Poeppl et al. 2013; Schiffer et al. 2007, 2017) and white (Cantor and Blanchard 2012; Cantor et al. 2008, 2015) matter in brain regions involved in sexual arousal (Tenbergen et al. 2015), including amygdala (Poeppl et al. 2013; Schiffer et al. 2007; Schiltz et al. 2007), hypothalamus and septal regions (Poeppl et al. 2013; Schiltz et al. 2007), as well as in the orbitofrontal cortex (OFC) and basal ganglia (Schiltz et al. 2007), areas with a relevant role in impulse inhibition and reward. Pedophiles also showed significant functional activation differences while viewing images depicting nude children and nude adults as compared to controls (Schiffer et al. 2008). Overall, brain imaging studies have revealed a widespread dysfunctional brain activity mainly encompassing the frontal, parietal and temporal lobes (Poeppl et al. 2011; Walter et al. 2007), as well as relevant subcortical structures (Sartorius et al. 2008). However, structural and functional abnormalities in pedophiles show considerable variability across studies. Furthermore, it is unclear to what extent these abnormalities are an incidental correlate rather than a cause of pedophilia (Mohnke et al. 2014; Tenbergen et al. 2015).

Psychiatric symptoms can emerge as a consequence of neurological insult (Keshavan and Kaneko 2013; McAllister 2008); thus, an effective approach commonly adopted by classical neuropsychology, is to investigate the neural basis of pedophilia is to study patients who develop pedophilic urges and/or behavior following focal brain lesions, referred to as "acquired pedophilia" (Camperio Ciani et al. 2019; Gilbert and Focquaert 2015). Unlike "idiopathic pedophilia", whose etiology remains unknown, acquired pedophilia occurs de novo in individuals who had never manifested pedophilic interests or urges earlier in life, as a symptom of an underlying neurological disorder (Devinsky et al. 2010; Fumagalli et al. 2015; Gilbert and Vranic 2015; Gilbert et al. 2016; Mendez and Shapira 2011; Mendez 2010; Mendez et al. 2000; Miller et al. 1986; Sartori et al. 2016; Scarpazza et al. 2018b). The causal inference is strongly indicated by the temporal relationship between the onset of the neurological disorder and the appearance of pedophilic behavior (Scarpazza et al. 2018a). Furthermore, pedophilic behavior recedes after the underlying neurological condition has been treated (Burns and Swerdlow 2003; Sartori et al. 2016). The first documented case of acquired pedophilia, reported in 1862 (von Krafft-Ebing 1897), was a 78 years-old man with no previous criminal record who sexually assaulted a 13 years-old child playing in the garden. Upon medical examination, the subject manifested memory deficits and tangential language and was unable to recognize the moral disvalue or the legal implications of his behavior. Eventually, he was diagnosed with dementia. More recent cases of acquired pedophilia in the literature include: a 40 years-old man with a tumor in the OFC (Burns and Swerdlow 2003); a 67 years-old man with hippocampal sclerosis (Mendez and Shapira 2011); a 50 years-old man with a glioma involving the thalamus, hypothalamus, ventral midbrain an pons (Miller et al. 1986). The above examples already indicate that the mere lesion localization is not enough to account for the neurological bases of acquired pedophilia, as different cases do implicate different brain regions.

Overall, brain imaging studies in idiopathic and acquired pedophilia are inconclusive, as they show subtle and inconsistent brain alterations in developmental pedophilia, and spatially heterogeneous brain lesions in acquired pedophilia. Furthermore, it is not clear whether and to what exent idiopathic and acquired pedophilia may share the same anatomical substrate.

Thus, the current study wished to: (i) identify the brain regions consistently impaired in idiopathic and acquired pedophilia; (ii) determine whether the two forms of pedophilia are associated with overlapping or distinct brain networks; (iii) link topographically defined regions with corresponding psychological processes, testing which kind of experiments are most likely to activate a given region, to give a cognitive/ psychological meaning to the detected alterations.

In order to identify brain regions consistently impaired in idiopathic pedophilia, a coordinate based meta-analysis using the Activation Likelihood Estimation (ALE) method was performed (Eickhoff et al. 2012). This approach revealed converging and consistent findings across different studies, underlying important nodes of network alteration in idiopathic pedophilia.

Because in acquired pedophilia only cases reports, with macroscopic neuroanatomical alterations, have been published, the above strategy cannot be adopted. Thus, we used a lesion network mapping approach to identify brain regions consistently impaired in acquired pedophilia (Darby et al. 2018a, b). By assuming that every brain region is a part of complex network, this method identifies regions functionally connected to a lesion (Avena-Koenigsberger et al. 2017). As a matter of fact, lesions causing the same symptoms tend to be functionally connected with the same brain regions (Darby et al. 2018a, b).

\section{Materials and methods}

\section{Idiopathic pedophilia}

\section{Study selection and data extraction}

An in-depth search was conducted on Pubmed up to January 2020. The following terms were used: ("pedophilia" OR 
"pedophilic behavior" OR "child* abuse") AND ("fMRI" OR "functional magnetic resonance imaging" OR "neural basis" OR "voxel based morphometry" OR "brain abnormal*"). A search for studies in review and meta-analysis articles and a reference tracing were also performed.

To be included in the analysis, studies had to meet the following criteria: (i) use structural (sMRI) or functional (fMRI) MRI; (ii) perform a whole brain analysis (i.e., studies performing only region of interest (ROI) analysis were excluded); (iii) be original peer-reviewed data; (iv) include both pedophilic individuals and a healthy control group (HC) or pedophilic individuals who committed and who did not commit sexual abuse; (v) have a sample size of at least five individuals per group; (vi) report results in a standardized coordinate space (e.g., Tailarach Atlas or Montreal Neurologic Institute, MNI).

Literature screening and selection was performed according with the PRISMA guidelines (Moher et al. 2009). Two authors (CS and MM) screened the data independently. A third opinion (UB) was sought in case of discordance. Characteristics such as sample size, age of participants, coordinate space, coordinates and statistical values were recorded.

\section{Statistical analysis}

For a quantitative assessment of inter-study concordance, the Activation Likelihood Estimation (ALE) method (Eickhoff et al. 2009; Laird et al. 2005; Turkeltaub et al. 2002) was applied to both structural and functional data, following the most recent guidelines (Müller et al. 2018).

The peaks of activation/deactivation or of increased/ decreased grey matter volume were used to generate an ALE map, using the revised ALE algorithm (Turkeltaub et al. 2012) running under Ginger ALE software (http://brainmap.org/ale/) version 3.0.2. This algorithm treats activated foci of brain regions as three-dimensional Gaussian probability distributions centered at the given coordinates (Eickhoff et al. 2009; Laird et al. 2005). The algorithm incorporates the size of the probability distributions by considering the sample size of each study. Moreover, it employs the random-effect rather than the fixed-effect inference, by testing the above-chance clustering between contrasts rather than between foci. If the study reported more than one contrast of interest (for instance, brain activation while seeing adult vs. child naked bodies), only the more representative contrast of the process of interest was selected. This procedure was applied to adjust for multiple contrasts from the same sample (Müller et al. 2018). Then, inference was sought regarding the regions in which the likelihood of activation reported in a particular set of experiments was higher than expected by chance. Tailarach coordinates were transformed into MNI using a linear transformation (Laird et al. 2010; Lancaster et al. 2007). Statistical parametric maps were thresholded using a cluster level family-wise error
(FWE) correction at $\mathrm{p}<0.05$ (cluster-forming threshold at voxel-level $\mathrm{p}<0.001$ (Eickhoff et al. 2016)). For explorative analyses only, a $p<0.001$ uncorrected threshold was used. The correspondent brain regions were identified using the SPM Anatomy toolbox (version 1.5) (Eickhoff et al. 2005). For further details on the ALE method please refer to previous publications (Eickhoff et al. 2009, 2012b; Turkeltaub et al. 2012).

\section{Acquired pedophilia}

\section{Study selection and data extraction}

Published cases of acquired pedophilia were identified through a systematic review (Camperio Ciani et al. 2019). To be included in the analysis, studies had to: (i) be original reports of late onset pedophilic behavior; (ii) report a documented neurological condition temporally associated with the emergence of the pedophilic behavior; (iii) have a clearly identifiable neural basis for the pedophilic behavior. Two authors (CS and UB) extracted and screened the data independently. A third opinion (MM) was sought in case of discordance. Information as age of the offender, etiology of the underlying neurological disorder, brain localization of neuroanatomical abnormalities and symptoms other than pedophilia were recorded.

\section{Statistical analysis}

The lesion network mapping analysis (Darby et al. 2018a, b) was run to determine whether these lesion locations were part of a common brain network.

First, the brain alterations associated with the onset of pedophilic behavior were identified in each individual patient and manually traced in consensus by two expert raters (CS and UB) on the axial image of a standardized template using the MRIcron software (available at http://www.mricro.com/ mricron) (Rorden and Brett 2000; Rorden et al. 2009). Then, the lesion outline was verified by an independent third rater (SF). Some of the patients presenting with de novo pedophilia were diagnosed with a behavioral variant of frontotemporal dementia (bvFTD); therefore, they did not present a spatially defined lesion that could be outlined. In order to identify the neural structures consistently impaired in bvFTD, a coordinate based meta-analysis was run on papers presenting structural or functional abnormalities in patients with bvFTD vs. healthy controls (see Supplementary Material A and B for details). The output of the meta-analysis was then transformed in a binary mask.

Second, traced lesions were used as individual seeds in a seed based connectivity analysis, using resting state fMRI data from one hundred healthy subjects randomly selected from a freely available dataset: https://openneuro.org/datasets/ 
ds000221. The brain functional connectivity with each lesion was determined by calculating the correlated time course between each lesion location and every other brain voxel using the resting-state data from each individual healthy control, as previously reported (Darby et al. 2018a, b). The results in all controls were combined into an average correlation (r), converted according to Fisher transformation ( $\mathrm{z}$ ) using the following formula:

$z=\frac{1}{2} \log \left(\frac{1+r}{1-r}\right)=\operatorname{arctanh}(r)$

and then modeled in a linear regression framework to obtain a $\mathrm{T}$ value for each individual voxel and each brain mask. Voxels were thresholded at $\mathrm{T}> \pm 17$ to create a binarized map of significantly functionally connected regions to the seed, that corresponded to an effect size of $\mathrm{R}^{2}=0.75$. An extent threshold of 50 voxels also was applied. In this way, the brain network impaired by the presence of each lesion was calculated. Finally, maps from each of the patients were combined to form the lesion network mapping overlap for the group, showing the number (and percentage) of patients with lesions functionally connected to each individual voxel. A stability analysis was performed by replicating the analyses using three different control groups, each with 25 healthy subjects (we kept the minimum effect size of $\mathrm{R}^{2}=0.75$, which implies a $\mathrm{T}> \pm 8.5$ ). Analyses were performed using SPM-CONN (2018b) adopting standard preprocessing and denoising steps.

\section{Behavioral profile}

To link topographically defined brain regions with the corresponding psychological process, we ran a behavioral profiling approach across databases of aggregation from activations experiments (Genon et al. 2018; Plachti et al. 2019). This approach identifies which kind of experiments are most likely to activate a given region. A reverse inference approach with statistical testing $(\mathrm{P}<0.05$ corrected for multiple comparisons) was performed on the identified clusters of voxels in BrainMap database (http://www.brainmap.org/), to reveal the Behavioral Domain and Paradigm Classes consistently associated with these regions.

\section{Results}

\section{Idiopathic pedophilia}

One hundred and eighty studies were identified. After excluding the papers that did not meet the inclusion criteria, 19 original articles were included. The screening procedure, summarized in the PRISMA diagram, and the reasons for excluding individual studies are reported in the Supplementary Material C.
The included studies are summarized in Table 1 and the full database reporting the coordinates is available in the Supplementary Material D. Briefly, the coordinate based meta-analysis comprises 20 experiments (one study (Kargel et al. 2015) included two independent groups of pedophiles), 240 foci, 436 pedophiles and 449 control individuals, of whom 302 were healthy controls, 50 were non sexual offenders, and 97 were pedophiles who did not commit sexual offenses toward children. Critically, the included studies were not completely independent as some came from the same laboratories and at least a partial sample overlap was reported in some studies.

Using a conservative statistical threshold, no significant results were found, though the power of the analysis would have been sufficient to achieve significant results (Eickhoff et al. 2016). For exploratory purposes only, the threshold was decreased to $p<0.001$ uncorrected. Using this liberal threshold, four clusters located in the middle occipital gyrus (coordinates: $-36,-78,2$ ), in the middle cingulate gyrus (coordinates: $8,-12,42$ and $12,-30,46$ ) and in the superior frontal gyrus (coordinates: $-17,24,45$ ) were detected (Fig. 1). Although the whole meta-analysis included some studies with partially overlapping samples, these studies did not contribute to the creation of significant clusters. Thus, the foci contributing to each cluster came from independent samples. For this reason, and given the exploratory nature of this second analysis, the meta-analysis was not repeated after removing the partially overlapping samples. The behavioral profiling analysis was not performed in order to avoid over-interpretation of statistically non-significant results.

\section{Acquired pedophilia}

Seventeen papers were identified through the literature search, for a total of nineteen cases that met the inclusion criteria (see Supplementary Material E for details on the excluded cases). Table 2 reports the age, etiology, neural basis and symptoms and signs presented by each patient.

Seven out of the 19 patients expressed hyper-sexuality and all of them manifested a more general impulse dis-control. Moral judgment/social cognition behavior (namely, the ability to understand the social and moral disvalue of their action, theory of mind, ability to discriminate right from wrong) was impaired in nine patients, spared in four, while no data were available for the remaining six cases.

Lesion localization was very heterogeneous, as reported in Table 2. Lesions were traced using the original anatomical scans of the patients in two cases (Sartori et al. 2016; Scarpazza et al. 2019); the images reported in the original publications in six cases (Alnemari et al. 2016; Burns and Swerdlow 2003; Frohman et al. 2002; Fumagalli et al. 2015; 
Table 1 Characteristics of the studies included in the ALE metaanalysis on idiopathic pedophilia

\begin{tabular}{|c|c|c|c|c|c|c|}
\hline & Reference & Ped. N & Contr. N & $\begin{array}{l}\text { Neuroimaging } \\
\text { technique }\end{array}$ & Contrast & $\begin{array}{l}\text { Number of } \\
\text { foci }\end{array}$ \\
\hline 1 & $\begin{array}{l}\text { (Schiffer et al. } \\
\text { 2007) }\end{array}$ & 18 & $24 \mathrm{HC}$ & sMRI & Pedophiles vs. HC & 20 \\
\hline 2 & $\begin{array}{l}\text { (Walter et al. } \\
\text { 2007) }\end{array}$ & 13 & $13 \mathrm{HC}$ & fMRI & Pedophiles vs. HC & 15 \\
\hline 3 & $\begin{array}{l}\text { (Sartorius et al. } \\
\text { 2008) }\end{array}$ & 10 & $10 \mathrm{HC}$ & fMRI & Pedophiles vs. HC & 2 \\
\hline 4 & $\begin{array}{l}\text { (Schiffer et al. } \\
\text { 2008) }\end{array}$ & 8 & $12 \mathrm{HC}$ & fMRI & Pedophiles vs. HC & 32 \\
\hline 5 & $\begin{array}{l}\text { (Schiffer } \\
\text { et al. 2008) }\end{array}$ & 11 & $12 \mathrm{HC}$ & fMRI & Pedophiles vs. HC & 9 \\
\hline 6 & $\begin{array}{l}\text { (Poeppl et al. } \\
\text { 2011) }\end{array}$ & 9 & $11 \mathrm{NSO}$ & fMRI & $\begin{array}{l}\text { Pedophiles vs. } \\
\text { NSO }\end{array}$ & 13 \\
\hline 7 & $\begin{array}{l}\text { (Ponseti et al. } \\
\text { 2012) }\end{array}$ & 24 & $18 \mathrm{HC}$ & fMRI & Pedophiles vs. HC & 25 \\
\hline 8 & $\begin{array}{l}\text { (Habermeyer } \\
\text { et al. 2013a) }\end{array}$ & 11 & $7 \mathrm{HC}$ & fMRI & Pedophiles vs. HC & 4 \\
\hline 9 & $\begin{array}{l}\text { (Habermeyer } \\
\text { et al. 2013b) }\end{array}$ & 8 & $8 \mathrm{HC}$ & fMRI & Pedophiles vs. HC & 12 \\
\hline 10 & $\begin{array}{l}\text { (Poeppl et al. } \\
\text { 2013) }\end{array}$ & 9 & $11 \mathrm{NSO}$ & SMRI & $\begin{array}{l}\text { Pedophiles vs. } \\
\text { NSO }\end{array}$ & 10 \\
\hline 11 & $\begin{array}{l}\text { (Cantor et al. } \\
\text { 2015) }\end{array}$ & 24 & $32 \mathrm{HC}$ & SMRI & Pedophiles vs. HC & 30 \\
\hline 12 & $\begin{array}{l}\text { (Gerwinn et al. } \\
\text { 2015) }\end{array}$ & 24 & $32 \mathrm{HC}$ & SMRI & Pedophiles vs. HC & 3 \\
\hline \multirow[t]{2}{*}{13} & $\begin{array}{l}\text { (Kargel et al. } \\
\text { 2015) }\end{array}$ & $\begin{array}{c}12 \\
\mathrm{CS}- \\
\mathrm{A}+\end{array}$ & $14 \mathrm{HC}$ & fMRI & Pedophiles vs. HC & 13 \\
\hline & & $\begin{array}{c}14 \\
\text { CS- } \\
\text { A- }\end{array}$ & $14 \mathrm{HC}$ & fMRI & Pedophiles vs. HC & 3 \\
\hline 14 & $\begin{array}{l}\text { (Cantor et al. } \\
\text { 2016) }\end{array}$ & 37 & $\begin{array}{l}39 \mathrm{HC}+28 \\
\mathrm{NSO}\end{array}$ & fMRI & $\begin{array}{l}\text { Pedophiles vs. (HC } \\
\quad+\text { NSO) }\end{array}$ & 23 \\
\hline 15 & $\begin{array}{c}\text { (Kargel et al. } \\
\text { 2017) }\end{array}$ & $\begin{array}{l}40 \\
\text { CS- } \\
\text { A+ }\end{array}$ & 37 CSA- & fMRI & CSA+vs. CSA- & 3 \\
\hline 16 & $\begin{array}{l}\text { (Massau et al. } \\
\text { 2017) }\end{array}$ & 31 & $19 \mathrm{HC}$ & fMRI & Pedophiles vs. HC & 4 \\
\hline 17 & $\begin{array}{l}\text { (Schiffer et al. } \\
\text { 2017) }\end{array}$ & $\begin{array}{l}58 \\
\mathrm{CS}- \\
\mathrm{A}+\end{array}$ & 60 CSA- & fMRI & CSA+vs. CSA- & 8 \\
\hline 18 & $\begin{array}{l}\text { (Ponseti et al. } \\
\text { 2017) }\end{array}$ & 60 & $55 \mathrm{HC}$ & fMRI & Pedophiles vs. HC & 9 \\
\hline 19 & $\begin{array}{l}\text { (Fonteille et al. } \\
\text { 2019) }\end{array}$ & 15 & $15 \mathrm{HC}$ & PET & Pedophiles vs. HC & 2 \\
\hline
\end{tabular}

Ped. $\mathrm{N}=$ Number of pedophiles; Contr. $\mathrm{N}=$ number of controls; $\mathrm{HC}=$ Healthy Controls; $\mathrm{NSO}=$ Non Sexual Offenders; $\mathrm{CSA}+=$ pedophiles who committed child sexual abuse; $\mathrm{CSA}-=$ pedophiles who did not commit child sexual abuse; sMRI = structural magnetic resonance images; $\mathrm{fMRI}=$ functional magnetic resonance images
Gilbert and Vranic 2015; Gilbert et al. 2016; Mendez et al. 2000); from a coordinate based meta-analysis on bvFTD in four cases Mendez and Shapira 2011; Mendez et al. 2000; Rainero et al. 2011; Scarpazza et al. 2018). In the remaining cases, lesions were traced following the description provided in the paper (Devinsky et al. 2010; Lesniak et al. 1972; Mendez and Shapira 2011; Miller et al. 1986; Regestein and Reich 1978) and following indications from expert neuroradiologists and neurosurgeons when needed. In one case (Devinsky et al. 2010), the author of the original publication verified the traced lesion.

Though the individual lesions had different locations, the lesion network mapping analysis revealed that $95 \%$ of them were part of a single brain network defined by functional connectivity with posterior midline structures (center of gravity coordinates: $0,-43,55)$, including the posterior cingulate 


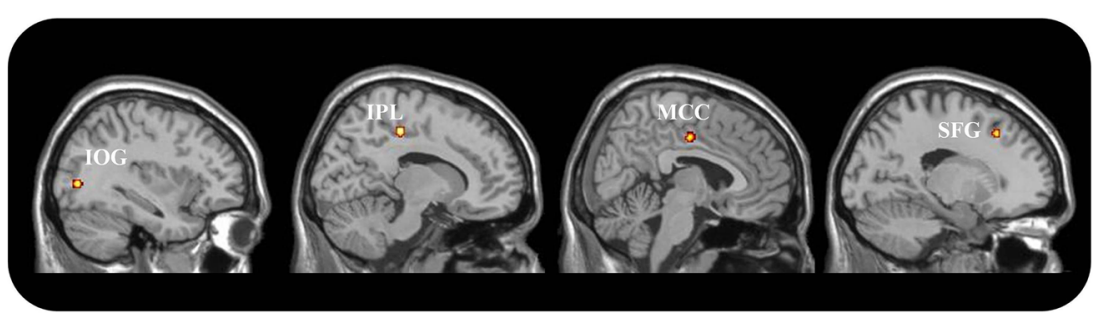

Fig. 1 Results of ALE-meta-analysis in idiopathic pedophilia. Results are presented in the sagittal view for illustrative purposes only at the liberal statistical threshold of $p<0.001$, uncorrected. IPL: Inferior Parietal Lobe;

cortex (PCC) and precuneus; the bilateral OFC (left coordinates: $-34,32,-17$; right coordinates: $36,30,-17)$ ); the right inferior temporal gyrus (ITG; coordinates: $52,-16,-28$ ), the left calcarine gyrus (coordinates: $-9,-56,7$ ) and the left fusiform gyrys (coordinates: -44, -63, -19) (Fig. 2). These results were replicated using also smaller control groups.

Interestingly, the behavioral profiling analysis (Table 3) highlighted that the identified regions are associated with social cognition (posterior midline structures and inferior temporal gyrus) and in particular with the theory of mind construct (posterior midline structures). Furthermore, a significant association was found between the right OFC and different functions covering emotions and action inhibition. Additionally, regions in the left hemisphere were associated with functions supporting object identification/interpretation, monitoring of information/discrimination judgments and autobiographical remembering.

\section{Discussion}

This study sought to: (i) identify consistent alterations associated with acquired and idiopathic pedophilia; (ii) understand whether and to what extent the two forms of pedophilia may share the same biological substrate; (iii) investigate whether consistent brain abnormalities may explain psychopathological features typically detected in pedophiles.

Of relevance, the lesion network mapping technique revealed that the neural bases of acquired pedophilia localize to a common resting state network, despite the high spatial heterogeneity of the individual lesions. Overall, these data support a shared neurobiological substrate in acquired pedophilia, as they reveal that the lesions chronologically associated with acquired pedophilic behavior are all functionally connected with a network involving the OFC areas, the posterior midline structures, the right inferior temporal gyrus and the left fusiform gyrus.

On the contrary, the ALE meta-analysis of whole brain neuroimaging studies in idiopathic pedophilia revealed no spatially convergent findings across studies, suggesting that idiopathic
MCC: Middle Cingulate Cortex; IOG: Inferior Occipital Gyrus; SFG = Superior Frontal Gyrus

pedophilia does not have consistent brain alterations that may be detected by structural or functional neuroimaging investigations. However, when lowering the statistical threshold, a few clusters of spatial convergence emerged in the superior frontal gyrus, middle cingulate and middle occipital gyrus. The different findings obtained from the analyses in idiopathic and acquired pedophilia may suggest that the two conditions may not rely on a shared neural base. Of note, the amygdala, which had been reported to be consistently impaired in pedophilia (Mohnke et al. 2014; Tenbergen et al. 2015), did not emerge from the current meta-analysis, even at the more liberal statistical threshold. This suggests that ROI analyses in original studies may have overestimated the real amygdala effects.

Thus, despite idiopathic and acquired pedophilia are usually considered as a whole in studies that investigate the neural basis of pedophilic behavior, they actually seem to be two distinct disorders. Indeed, they differ in their etiology: while idiopathic pedophilia is a paraphilia, namely a psychiatric disorder included within the DSM5, acquired pedophilia is a symptom resulting from an underlying neurological insult. Second, modus operandi in the two conditions widely differs: while idiopathic pedophiles are characterized by a highly predatory style (Fagan et al. 2002; Hall and Hall 2007), acquired pedophiles usually show a dis-organized behavior, characterized by dis-control of impulses (Camperio Ciani et al. 2019; Scarpazza et al. 2018). Third, the temporal insurgence of the pedophilic urges is an additional factor that contributes to the differential diagnosis: while idiopathic pedophilia typically first appears in adolescence and is stable across the lifespan(Beech et al. 2016), the age of the onset of acquired pedophilia is typically well after adolescence and varies depending on the time of onset of the underlying neurological lesion (Camperio Ciani et al. 2019).

The current results provide further support to the existence of two distinct neural networks involved in the two forms of pedophilia, corroborating the emerging idea that they might be two different disorders/ entities(Camperio Ciani et al. 2019).

Interestingly, the data driven behavioral profiling on acquired pedophilia indicated impaired connectivity between lesions causing acquired pedophilia and regions crucial for social cognition (posterior midline structures and right ITG), specifically theory of mind (posterior midline structures), emotion recognition (right 
Table 2 Clinical characteristics of the patients with acquired pedophilia

\begin{tabular}{|c|c|c|c|c|c|}
\hline Reference & Age & Neural basis & Etiology & Medication & Symptoms \\
\hline (Lesniak et al. 1972) & 60 & $\begin{array}{l}\text { Right Frontal } \\
\text { lobe }\end{array}$ & $\begin{array}{l}\text { Tumor (benign } \\
\text { glioma) }\end{array}$ & Not reported & $\begin{array}{l}\text { Coprolalia, exhibitionism, quick } \\
\text { tempered and irritable, impairment of } \\
\text { smell, hypersexuality }\end{array}$ \\
\hline $\begin{array}{l}\text { (Regestein and Reich } \\
\text { 1978) Case } 1\end{array}$ & 56 & $\mathrm{OFC}$ & $\begin{array}{l}\text { Supracellar } \\
\text { meningioma }\end{array}$ & Not reported & $\begin{array}{l}\text { Decreased vision in the left eye, right } \\
\text { side facial weakness, hyperreflexia, } \\
\text { personality change, lack of initiative, } \\
\text { impaired moral reasoning, impaired } \\
\text { prosody, absence of insight }\end{array}$ \\
\hline $\begin{array}{l}\text { (Miller et al. 1986) } \\
\quad \text { Case } 5\end{array}$ & 50 & $\begin{array}{l}\text { Left brainstem, } \\
\text { hypothalamus, } \\
\text { thalamus }\end{array}$ & $\begin{array}{l}\text { Hypercellular grade } 3 \\
\text { astrocytoma }\end{array}$ & Not reported & $\begin{array}{l}\text { Subtle personality changes, poor } \\
\text { financial and moral judgement, } \\
\text { hemiparesis, hemiataxia }\end{array}$ \\
\hline $\begin{array}{l}\text { (Mendez et al. 2000) Case } \\
\text { 1, Also described in } \\
\text { (Mendez and Shapira } \\
\text { 2011; Mendez 2010) } \\
\text { Case 1 }\end{array}$ & 60 & $\begin{array}{l}\text { Atrophy in the } \\
\text { frontal and } \\
\text { temporal } \\
\text { cortices }\end{array}$ & bvFTD & $\begin{array}{l}\text { Paroxetine; valproate; } \\
\text { estrogens }\end{array}$ & $\begin{array}{l}\text { Decline in social and personal } \\
\text { awareness, dis-inhibition, } \\
\text { hyperorality, lack of insight, } \\
\text { utilization behavior, echolalia, verbal } \\
\text { stereotypies, impaired memory, lack } \\
\text { of abstract thinking, compulsive } \\
\text { behaviours }\end{array}$ \\
\hline $\begin{array}{l}\text { (Mendez et al. 2000) Case } \\
\text { 2, also described in } \\
\text { (Mendez and Shapira } \\
\text { 2011) case } 8\end{array}$ & 67 & $\begin{array}{l}\text { Bilateral } \\
\text { hyppocampi }\end{array}$ & $\begin{array}{l}\text { Hippocampal } \\
\text { sclerosis }\end{array}$ & $\begin{array}{l}\text { Sertraline (history of cocaine } \\
\text { abuse) }\end{array}$ & $\begin{array}{l}\text { Severe memory difficulties, } 24 / 30 \text { at } \\
\text { MMSE, normal language abilities }\end{array}$ \\
\hline (Frohman et al. 2002) & 38 & $\begin{array}{l}\text { Hypothalamus, } \\
\text { brainstem, } \\
\text { right } \\
\text { sub-insula } \\
\text { regions, basal } \\
\text { ganglia }\end{array}$ & Multiple Sclerosis & $\begin{array}{l}\text { Interferon beta- } 1 \mathrm{~b} \text { (for multi- } \\
\text { ple sclerosis); } \\
\text { fluvoxamine maleate; } \\
\text { medroxyprogesterone ace- } \\
\text { tate }\end{array}$ & $\begin{array}{l}\text { Binocular diplopia, dysarthria, ataxia, } \\
\text { poor judgement, impulsivity, } \\
\text { dis-inhibition, perseveration, } \\
\text { hypersexuality }\end{array}$ \\
\hline $\begin{array}{l}\text { (Burns and Swerdlow } \\
\text { 2003) }\end{array}$ & 40 & Right OFC & Hemangio-pericytoma & $\begin{array}{l}\text { Fluoxetine hydrochloride, } \\
\text { amlodipine besylate, } \\
\text { metoclopramide } \\
\text { hydrochloride, } \\
\text { medroxyprogesterone } \\
\text { acetate }\end{array}$ & $\begin{array}{l}\text { Dis-inhibition, spared moral reasoning, } \\
\text { constructional apraxia, writing } \\
\text { illegible, balance problems, } \\
\text { incontinence }\end{array}$ \\
\hline (Devinsky et al. 2010) & 51 & $\begin{array}{l}\text { Right mesial } \\
\text { temporal lobe }\end{array}$ & Gangloglioma & $\begin{array}{l}\text { Antiepileptic drugs; } \\
\text { quetiapine and sertraline } \\
\quad \text { (after the arrest) }\end{array}$ & $\begin{array}{l}\text { Musical hallucinations, personality } \\
\text { changes, irritability, dis-inhibition } \\
\text { (manifesting with Kluver-Bucy } \\
\text { symptoms of hyperphagia, } \\
\text { coprophilia), hypersexuality }\end{array}$ \\
\hline (Rainero et al. 2011) & 49 & $\begin{array}{l}\text { Bilateral frontal } \\
\text { lobe atrophy }\end{array}$ & bvFTD & Not reported & $\begin{array}{l}\text { Deficit in episodic memory, verbal } \\
\text { aggressiveness, severe impairment in } \\
\text { frontal functions as revealed by the } \\
\text { neuropsychological assessment, } \\
\text { social detachment, reduced insight } \\
\text { and disease awareness }\end{array}$ \\
\hline $\begin{array}{l}\text { (Mendez and Shapira } \\
\text { 2011) Case } 2\end{array}$ & 67 & $\begin{array}{l}\text { Bilateral frontal } \\
\text { lobe atrophy }\end{array}$ & bvFTD & Haloperidol & $\begin{array}{l}\text { Insidious Personality change, lack of } \\
\text { insight, dis-inhibition, compulsive } \\
\text { acts, hyperorality, decreased verbal } \\
\text { fluency, hypersexuality }\end{array}$ \\
\hline $\begin{array}{l}\text { (Mendez and Shapira } \\
\text { 2011) Case } 4\end{array}$ & 82 & $\begin{array}{l}\text { Right globus } \\
\text { pallidus }\end{array}$ & Vascular dementia & Valproate; trazodone & $\begin{array}{l}\text { Sudden onset of personality changes, } \\
\text { dis-inhibition, baby talking, profane } \\
\text { language, perseveration, } \\
\text { stimulus-bound behavior, hypersexu- } \\
\text { ality }\end{array}$ \\
\hline \multirow[t]{2}{*}{$\begin{array}{l}\text { (Mendez and Shapira } \\
\text { 2011) Case } 6\end{array}$} & 32 & $\begin{array}{l}\text { Caudate, } \\
\text { putamen and } \\
\text { striatum } \\
\text { bilaterally }\end{array}$ & Huntington's disease & Haloperidol; Sertraline & $\begin{array}{l}\text { Personality changes, dysartria, } \\
\text { aggressiveness, decreased verbal } \\
\text { fluency, deficit in executive } \\
\text { functions, lack of insight, impulsivity }\end{array}$ \\
\hline & 59 & Right Pallidum & Right Pallidotomy & & \\
\hline
\end{tabular}


Table 2 (continued)

\begin{tabular}{|c|c|c|c|c|c|}
\hline Reference & Age & Neural basis & Etiology & Medication & Symptoms \\
\hline $\begin{array}{l}\text { (Mendez and Shapira } \\
\text { 2011) Case } 7\end{array}$ & & & & $\begin{array}{l}\text { Carbidopa/levodopa; } \\
\text { pramipexole }\end{array}$ & $\begin{array}{l}\text { Spared insight of behavior, } \\
\text { dis-inhibition, hypersexuality }\end{array}$ \\
\hline (Fumagalli et al. 2015) & 63 & $\begin{array}{l}\text { Right vmPFC, } \\
\text { left PFC }\end{array}$ & TBI & $\begin{array}{l}\text { Irbesartan for hypertension; } \\
\text { paroxetine }\end{array}$ & $\begin{array}{l}\text { Irritability, uncontrollable emotional } \\
\text { reactions, mild dis-inhibition, } \\
\text { dysexecutive syndrome, impulsivity }\end{array}$ \\
\hline $\begin{array}{l}\text { (Gilbert and Vranic 2015; } \\
\text { Gilbert et al. 2016) }\end{array}$ & 48 & Left frontal lobe & $\begin{array}{l}\text { Glioblastoma } \\
\text { multiforme }\end{array}$ & $\begin{array}{l}\text { Levetiracetam (Antiepileptic } \\
\text { drugs); diazepam; }\end{array}$ & $\begin{array}{l}\text { Epilepsy, depression, apatia, } \\
\text { aggressiveness, confusion, } \\
\text { dis-orientation }\end{array}$ \\
\hline (Alnemari et al. 2016) & $\begin{array}{r}\text { Early } \\
20\end{array}$ & $\begin{array}{l}\text { Basal frontal and } \\
\text { bilateral } \\
\text { temporal }\end{array}$ & $\begin{array}{l}\text { Epidural hematoma } \\
\text { from TBI }\end{array}$ & Not reported & $\begin{array}{l}\text { Attention deficit, difficulty sleeping, } \\
\text { irritability, and unspecified } \\
\text { behavioral changes }\end{array}$ \\
\hline $\begin{array}{l}\text { (Sartori et al. 2016; } \\
\quad \text { Scarpazza et al. 2018) }\end{array}$ & 64 & $\begin{array}{l}\text { OFC+ } \\
\text { Hypothalamus }\end{array}$ & Clivus Chordoma & Not reported & $\begin{array}{l}\text { Dis-inhibition, deficit social cognition, } \\
\text { deficit emotion attribution, deficit in } \\
\text { understanding morality, } \\
\text { anoso-agnosia }\end{array}$ \\
\hline $\begin{array}{l}\text { (Scarpazza et al. } \\
\text { 2018) Case } 1\end{array}$ & 70 & $\begin{array}{c}\text { Bilateral frontal } \\
\text { lobe atrophy }\end{array}$ & bvFTD & Anti-dopaminergic drugs & $\begin{array}{l}\text { Deficit in critical thinking, abstract } \\
\text { thinking, severe deficit in attention, } \\
\text { behavioral control, impulse } \\
\text { inhibition, preservative behavior and } \\
\text { an inability to foresee the } \\
\text { consequences of his own actions, } \\
\text { hypersexuality }\end{array}$ \\
\hline $\begin{array}{l}\text { (Scarpazza et al. } \\
\text { 2018) Case } 2\end{array}$ & 60 & $\begin{array}{l}\text { Frontal and } \\
\text { parietal lobes }\end{array}$ & $\begin{array}{r}\text { Meningothelial } \\
\text { Meningioma }\end{array}$ & Delorazepam & $\begin{array}{l}\text { Constructional apraxia, impaired } \\
\text { sustained attention, difficulty to } \\
\text { inhibit the automatic answer and } \\
\text { behavior; impairment in problem } \\
\text { solving and planning abilities, } \\
\text { perseveration. }\end{array}$ \\
\hline
\end{tabular}

OFC = OrbitoFrontal Cortex; vmPFC = VentroMedial Prefrontal Cortex; PFC = Prefrontal Cortex; bvFTD = behavioral variant Fronto Temporal Dementia; TBI $=$ Traumatic Brain Injury

OFC), impulse control (right OFC), semantic interpretation of cues (left OFC, L fusiform gyrus). It is noteworthy that these results match well with the aberrant behavior pattern described in acquired pedophiles. The observation of altered activity in a key region for impulse inhibition fits perfectly with previous evidence from single case description of patients with acquired pedophilia, in whom dis-inhibition is invariably present (Devinsky et al. 2010; Gilbert and Focquaert 2015; Mendez and Shapira 2011; Miller et al. 1986; Sartori et al. 2016; Scarpazza et al. 2018). Dis-inhibition also was recently reported to be a red flag suggesting an acquired origin of pedophilic behavior (Camperio Ciani et al. 2019) and accounts for the disorganized modus operandi of these sexual offenders. Similarly, the observation of altered activity in key regions for social cognition, in particular for theory of mind and emotion recognition, fits well with the patient inability to understand what is morally wrong (Camperio Ciani et al. 2019; Frohman et al. 2002; Fumagalli et al. 2015; Mendez and Shapira 2011; Miller et al. 1986; Regestein and Reich 1978; Sartori et al. 2016; Scarpazza et al. 2018).

Of note, these results are specific for acquired pedophilia, as idiopathic pedophilia was not associated with impairments in the same brain regions, even when the statistical threshold was lowered. Idiopathic pedophiles are characterized by a different profile of neuropsychological impairment, consisting in lower IQ and working memory performance, coupled with a higher performance in abstract reasoning and planning, as compared to non pedophiles (Tenbergen et al. 2015). Although difficulties in behavioral inhibition and empathy have also been observed in idiopathic pedophiles, the reported effect size is very small (Tenbergen et al. 2015), suggesting that individual inferences in idiopathic pedophilia are relevant. Furthermore, idiopathic pedophilia has a high comorbidity with other psychiatric disorders, in particular with personality disorders (Fagan et al. 2002; Geer et al. 2000; Kruger and Schiffer 2011; Raymond et al. 1999). Thus, it is difficult to disentangle to what extent the reported neuropsychological impairments are related to pedophilia itself or to the associated psychiatric condition.

Importantly, cognitive abilities associated with brain regions that are impaired in acquired pedophiles comprise impulse control, emotion recognition and social cognition/theory of mind, all functions that are pivotal for self-determination. Indeed, according to the neuroscientific INUS (Insufficient 
Fig. 2 Brain regions consistently involved in acquired pedophilia. $\mathrm{OFC}=$ OrbitoFrontal Cortex, $\mathrm{PCC}=$ Posterior Cingulate Cortex ; ITG = Inferior Temporal Gyrus; $\mathrm{R}=$ right; $\mathrm{L}=$ left

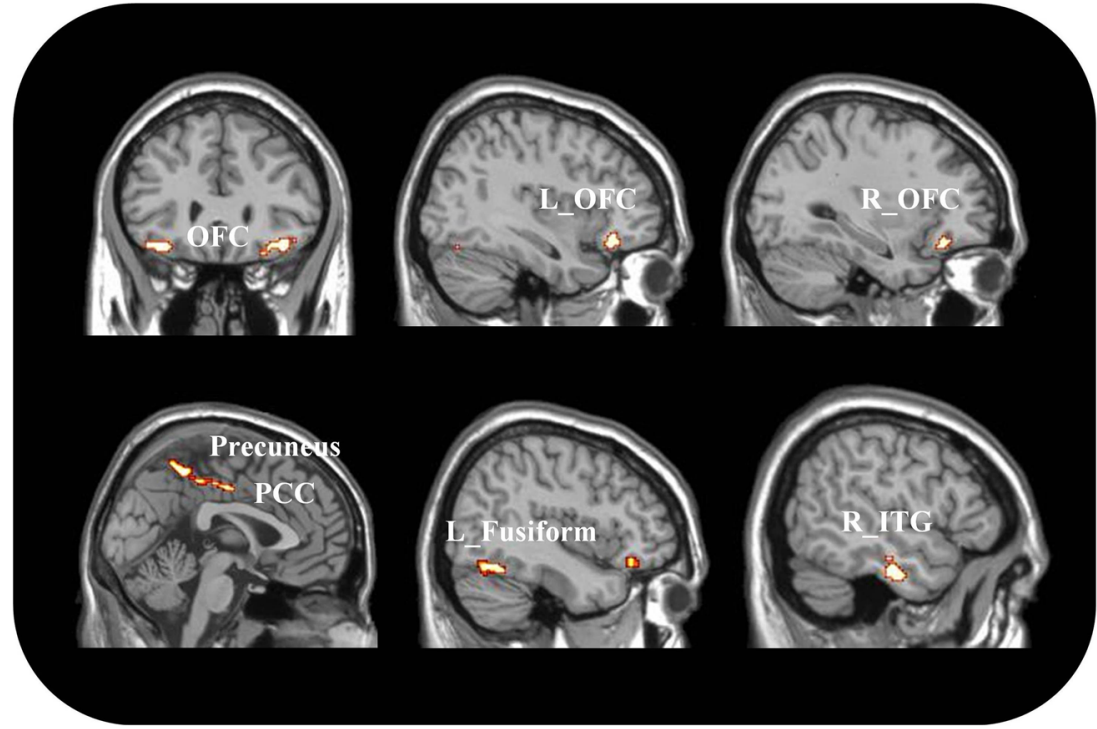

but Non-redundant parts of Unnecessary but Sufficient conditions) model of causation (Anckarsäter et al. 2009), the concomitant impairment in impulse control and social cognition would account for the acquired pedophilic behavior. According to this model, while none of these impaired functions taken by itself in isolation could explain the insurgence of pedophilic behavior, all together they can.

Acquired pedophilia may be considered as a behavioral manifestation of pre-existent latent pedophilic urges due to general impulse dis-inhibition (Mohnke et al. 2014). Interestingly, the application to acquired pedophilia of the INUS model of causation, which requires the concomitant impairment in both social cognition and action inhibition, makes this hypothesis less likely. This claim, however, needs further exploration.

As a final note, the result that idiopathic and acquired pedophilia are characterized by distinct neural networks highlights the need to reconsider the approach of using neurological disorders to investigate the basis of psychiatric conditions or complex behaviors (Darby et al. 2018a). Indeed, individual psychiatric symptoms that may appear within the clinical picture of a neurological condition, like hallucinations or thought disorders in patients with epilepsy or brain tumors, not necessarily may have a neural substrate identical to the one underlying their manifestation in the course of a psychiatric disorder. As a matter of fact, psychiatric and neurological disorders have been proven to have distinct neuroimaging correlates that arguably may reflect distinct neuropathologies (Crossley et al. 2015).

This study is not free from drawbacks. Specifically, some of the seeds of the lesion network analysis were traced without a 2D figure from the original paper so that consultation with neuroradiologists was necessary to identify the most likely lesion(s). Results of neuroimaging analyses, however, strongly reflect cognitive/behavioral deficits observed in those patients, corroborating the plausibility of our analysis. Second, the lesion network analysis was run using only a relatively small sample of healthy controls (one hundred subjects). The additional analyses we run, however, corroborated the robustness of the results, which remained stable using different control groups of 25 healthy controls. Finally, in the lesion network mapping analysis we could not take into account potential medication effects in the

Table 3 Results of the behavioral profiling analysis

\begin{tabular}{|c|c|c|c|}
\hline Cluster & $\begin{array}{l}\text { Size } \\
(k)\end{array}$ & $\begin{array}{l}\text { BrainMap } \\
\text { Behavioral } \\
\text { Domains }\end{array}$ & $\begin{array}{l}\text { BrainMap Paradigm } \\
\text { Classes }\end{array}$ \\
\hline $\begin{array}{l}\text { Posterior } \\
\text { midline } \\
\text { regions } \\
\text { (precuneus, } \\
\text { PCC) }\end{array}$ & 131 & Social Cognition & Theory of mind \\
\hline Left OFC & 122 & $\begin{array}{l}\text { Language } \\
\text { Cognition: } \\
\text { Semantics, } \\
\text { Gustation }\end{array}$ & $\begin{array}{l}\text { Semantic } \\
\text { Monitor/discrimination }\end{array}$ \\
\hline Right OFC & 62 & $\begin{array}{l}\text { Emotion, } \\
\text { Gustation, } \\
\text { Action } \\
\text { Inhibition }\end{array}$ & ns \\
\hline Right ITG & 96 & Social Cognition & ns \\
\hline $\begin{array}{l}\text { Left Fusiform } \\
\text { gyrus }\end{array}$ & 95 & $\begin{array}{l}\text { Language } \\
\text { Cognition: } \\
\text { Semantics, } \\
\text { Speech, } \\
\text { Phonology. } \\
\text { Action execution: } \\
\text { Speech, Action } \\
\text { observation }\end{array}$ & $\begin{array}{l}\text { Face; } \\
\text { monitor/discrimination; } \\
\text { Phonological discrimi- } \\
\text { nation; film viewing; } \\
\text { naming (overt); naming } \\
\text { (covert) }\end{array}$ \\
\hline $\begin{array}{l}\text { Left Calcarine } \\
\text { Gyrus }\end{array}$ & 55 & $\begin{array}{l}\text { Explicit } \\
\text { (long-term) } \\
\text { memory }\end{array}$ & Autobiographical recall \\
\hline
\end{tabular}

PCC $=$ Posterior Cingulate Cortex OFC $=$ OrbitoFrontal Cortex IFG = Inferior Temporal Gysus; ns = non significant results 
individual patients. However, the original papers indicate that drugs were usually administered after symptoms insurgence, thus the impact of pharmacotherapy for the purposes of the current study is limited. Future studies should assess potential effects of pharmacotherapy.

In summary, the results of this study pinpoint aberrant brain activity related to acquired but not to idiopathic pedophilia. All the lesions causing acquired pedophilia localized to a shared resting state network including the posterior midlines structures, the right inferior temporal gyrus and the bilateral OFC, regions consistently involved in social cognition, theory of mind, emotion recognition and action inhibition. Alterations of these neuropsychological functions have been consistently described in individual reports of acquired pedophiles, in line with the observed results. Interpreting these findings in light of the INUS model of causation is relevant to better characterize these patients and to develop novel therapeutic and rehabilitative strategies (McGorry et al. 2014). Further researches in larger samples are needed to corroborate these results.

Supplementary Information The online version contains supplementary material available at https://doi.org/10.1007/s11682-020-00442-z.

Acknowledgements CS was supported by a grant from the University of Padua (Supporting TAlent in ReSearch @ University of Padua - STARS Grants 2017). The present study was carried out within the scope of the research program "Dipartimenti di Eccellenza" (art.1, commi 314-337 legge 232/2016), which was supported by a grant from MIUR to the Department of General Psychology, University of Padua.

Author contributions CS, PP, SF, ASCC (study conception and design); $\mathrm{CS}, \mathrm{MM}, \mathrm{UB}$ (performed the systematic search of the literature); CS, $\mathrm{MM}, \mathrm{UB}$ (run the meta-analysis and manually traced the lesions); CS, LF, SG, LM, EB, CC, JP, NN (run the statistical analysis); CS, ASCC, LF, UB, SG (drafted the paper); PP, SF, GS, LF, SG (provided critical revision of the manuscript); all authors (contributed to the interpretation of the findings, contributed with important intellectual content to the paper and approved the final version of the manuscript).

Funding Open Access funding provided by Università degli Studi di Padova.

\section{Compliance with ethical standards}

Conflict of interest The authors declare no conflict of interest.

Ethical statements In this paper, a re-analysis of already published data was performed. For this reason, the patient informed consent was not requested.

Ethical approval All the procedures performed in studies involving human participants were in accordance with the ethical standards of the respective institutional and/or national research Committees and with the 1964 Helsinki Declaration and its later amendments or comparable ethical standards.

Open Access This article is licensed under a Creative Commons Attribution 4.0 International License, which permits use, sharing, adaptation, distribution and reproduction in any medium or format, as long as you give appropriate credit to the original author(s) and the source, provide a link to the Creative Commons licence, and indicate if changes were made. The images or other third party material in this article are included in the article's Creative Commons licence, unless indicated otherwise in a credit line to the material. If material is not included in the article's Creative Commons licence and your intended use is not permitted by statutory regulation or exceeds the permitted use, you will need to obtain permission directly from the copyright holder. To view a copy of this licence, visit http://creativecommons.org/licenses/by/4.0/.

\section{References}

Alnemari, A. M., Mansour, T. R., Buehler, M., \& Gaudin, D. (2016). Neural basis of pedophilia: Altered sexual preference following traumatic brain injury. International Journal of Surgery Case Reports, 25, 221-224. https://doi.org/10.1016/j.ijscr.2016.06.035.

American Psychiatric Association. (2013). Diagnostic and statistical manual of mental disorders (5th ed.). Washington, DC: Publisher.

Anckarsäter, H., Radovic, S., Svennerlind, C., Holund, P., \& Radovic, F. (2009). Mental disorder is a cause of crime: the cornerstone of forensic psychiatry. International Journal of Law and Psychiatry, $32(6), 342-347$.

Avena-Koenigsberger, A., Misic, B., \& Sporns, O. (2017). Communication dynamics in complex brain networks. Nature Reviews. Neurology, 19(1), 17-33. https://doi.org/10.1038/nrn. 2017.149.

Beech, A. R., Miner, M. H., \& Thornton, D. (2016). Paraphilias in the DSM-5. Annual Review of Clinical Psychology, 12, 383-406. https://doi.org/10.1146/annurev-clinpsy-021815-093330.

Burns, J. M., \& Swerdlow, R. H. (2003). Right orbitofrontal tumor with pedophilia symptom and constructional apraxia sign. Archives of Neurology, 60(3), 437-440.

Camperio Ciani, A. S., Scarpazza, C., Covelli, V., \& Battaglia, U. (2019). Profiling acquired pedophilic behavior: Retrospective analysis of 66 Italian forensic cases of pedophilia. International Journal of Law and Psychiatry, 67, 101508. https://doi.org/10.1016/j.ijlp.2019. 101508.

Cantor, J. M., \& Blanchard, R. (2012). White matter volumes in pedophiles, hebephiles, and teleiophiles. Archives of Sexual Behavior, 41(4), 749-752. https://doi.org/10.1007/s10508-012-9954-2.

Cantor, J. M., Kabani, N., Christensen, B. K., Zipursky, R. B., Barbaree, H. E., Dickey, R., \& Blanchard, R. (2008). Cerebral white matter deficiencies in pedophilic men. Journal of Psychiatric Research, 42(3), 167-183. https://doi.org/10.1016/j.jpsychires.2007.10.013.

Cantor, J. M., Lafaille, S., Soh, D. W., Moayedi, M., Mikulis, D. J., \& Girard, T. A. (2015). Diffusion Tensor Imaging of Pedophilia. Archives of Sexual Behavior, 44(8), 2161-2172. https://doi.org/10. 1007/s10508-015-0629-7.

Cantor, J. M., Lafaille, S. J., Hannah, J., Kucyi, A., Soh, D. W., Girard, T. A., \& Mikulis, D. J. (2016). Independent component analysis of resting-state functional magnetic resonance imaging in pedophiles. The Journal of Sexual Medicine, 13(10), 1546-1554. https://doi.org/ 10.1016/j.jsxm.2016.08.004.

Crossley, N. A., Scott, J., Ellison-Wright, I., \& Mechelli, A. (2015). Neuroimaging distinction between neurological and psychiatric disorders. The British Journal of Psychiatry, 207(5), 429-434. https:// doi.org/10.1192/bjp.bp.114.154393.

Darby, R. R., Horn, A., Cushman, F., \& Fox, M. D. (2018a). Lesion network localization of criminal behavior. Proceedings of the National Academy of Sciences of the United States of America, 115(3), 601-606. https://doi.org/10.1073/pnas.1706587115. 
Darby, R. R., Joutsa, J., Burke, M. J., \& Fox, M. D. (2018b). Lesion network localization of free will. Proceedings of the National Academy of Sciences of the United States of America, 115(42), 10792-10797. https://doi.org/10.1073/pnas.1814117115.

Devinsky, J., Sacks, O., \& Devinsky, O. (2010). Kluver-Bucy syndrome, hypersexuality, and the law. Neurocase, 16(2), 140-145. https://doi. org/10.1080/13554790903329182.

Eickhoff, S. B., Bzdok, D., Laird, A. R., Kurth, F., \& Fox, P. T. (2012). Activation likelihood estimation meta-analysis revisited. Neuroimage, 59(3), 2349-2361. https://doi.org/10.1016/j. neuroimage.2011.09.017.

Eickhoff, S. B., Bzdok, D., Laird, A. R., Kurth, F., \& Fox, P. T. (2012b). Activation likelihood meta-analysis revisited. Neurolmage, 59, 8593.

Eickhoff, S. B., Laird, A. R., Grefkes, C., Wang, L. E., Zilles, K., \& Fox, P. T. (2009). Coordinate based activation likelihood estimation meta-analysis of neuroimaging data: a random effects approach based on empirical estimates of spatial uncertainty. Human Brain Mapping, 30, 2907-2926.

Eickhoff, S. B., Nichols, T. E., Laird, A. R., Hoffstaedter, F., Amunts, K., Fox, P. T., ... Eickhoff, C. R. (2016a). Behavior, sensitivity, and power of activation likelihood estimation characterized by massive empirical simulation. Neuroimage, 137, 70-85. https://doi.org/10. 1016/j.neuroimage.2016a.04.072.

Eickhoff, S. B., Stephan, K. E., Mohlberg, H., Grefkes, C., Fink, G. R., Amunts, K., \& Zilles, K. (2005). A new SPM toolbox for combining probabilistic cytoarchitectonic maps and functional imaging data. Neuroimage, 25(4), 1325-1335. https://doi.org/10.1016/j. neuroimage.2004.12.034.

Fagan, P. J., Wise, T. N., Schmidt, C. W., Jr., \& Berlin, F. S. (2002). Pedophilia. JAMA, 288(19), 2458-2465. https://doi.org/10.1001/ jama.288.19.2458

Fonteille, V., Redoute, J., Lamothe, P., Straub, D., Lavenne, F., Le Bars, D., \& Stoleru, S. (2019). Brain processing of pictures of children in men with pedophilic disorder: A positron emission tomography study. Neuroimaging Clinics, 21, 101647. https://doi.org/10.1016/ j.nicl.2018.101647.

Frohman, E. M., Frohman, T. C., \& Moreault, A. M. (2002). Acquired sexual paraphilia in patients with multiple sclerosis. Archives of Neurology, 59(6), 1006-1010.

Fumagalli, M., Pravettoni, G., \& Priori, A. (2015). Pedophilia 30 years after a traumatic brain injury. Neurological Sciences, 36(3), 481482. https://doi.org/10.1007/s10072-014-1915-1.

Geer, J. H., Estupinan, L. A., \& Manguno-Mire, G. M. (2000). Empathy, social skills, and other relevant cognitive processes in rapists and child molesters. Aggression and Violent Behavior, 5, 99-126.

Genon, S., Reid, A., Langner, R., Amunts, K., \& Eickhoff, S. B. (2018). How to characterize the function of a brain region. Trends in Cognitive Sciences, 22(4), 350-364. https://doi.org/10.1016/j.tics. 2018.01.010

Gerwinn, H., Pohl, A., Granert, O., van Eimeren, T., Wolff, S., Jansen, O., \& Ponseti, J. (2015). The (in)consistency of changes in brain macrostructure in male paedophiles: A combined T1-weighted and diffusion tensor imaging study. Journal of Psychiatric Research, 68, 246-253. https://doi.org/10.1016/j.jpsychires.2015.07.002.

Gilbert, F., \& Focquaert, F. (2015). Rethinking responsibility in offenders with acquired paedophilia: punishment or treatment? International Journal of Law and Psychiatry, 38, 51-60. https://doi.org/10.1016/j. ijlp.2015.01.007.

Gilbert, F., \& Vranic, A. (2015). Paedophilia, invasive brain surgery, and punishment. The Journal of Bioethical Inquiry, 12(3), 521-526. https://doi.org/10.1007/s11673-015-9647-3.

Gilbert, F., Vranic, A., \& Viaña, J. M. N. (2016). Acquired pedophilia and moral responsibility. AJOB Neuroscience, 7(4), 209-2011.

Habermeyer, B., Esposito, F., Handel, N., Lemoine, P., Kuhl, H. C., Klarhofer, M., ... Graf, M. (2013a). Response inhibition in pedophilia: an FMRI pilot study. Neuropsychobiology, 68(4), 228-237. doi:10.1159/000355295.

Habermeyer, B., Esposito, F., Handel, N., Lemoine, P., Klarhofer, M., Mager, R., \& Graf, M. (2013b). Immediate processing of erotic stimuli in paedophilia and controls: a case control study. $B M C$ Psychiatry, 13, 88. https://doi.org/10.1186/1471-244X-13-88.

Hall, R. C., \& Hall, R. C. (2007). A profile of pedophilia: definition, characteristics of offenders, recidivism, treatment outcomes, and forensic issues. Mayo Clinic Proceedings, 82(4), 457-471. https:// doi.org/10.4065/82.4.457.

Hanson, R. K., Morton, K. E., \& Harris, A. J. (2003). Sexual offender recidivism risk: what we know and what we need to know. Annals of the New York Academy of Sciences, 989, 154-166. discussion 236 146.

Kargel, C., Massau, C., Weiss, S., Walter, M., Borchardt, V., Krueger, T. H., \& Schiffer, B. (2017). Evidence for superior neurobiological and behavioral inhibitory control abilities in non-offending as compared to offending pedophiles. Human Brain Mapping, 38(2), 1092-1104. https://doi.org/10.1002/hbm.23443.

Kargel, C., Massau, C., Weiss, S., Walter, M., Kruger, T. H., \& Schiffer, B. (2015). Diminished functional connectivity on the road to child sexual abuse in pedophilia. The Journal of Sexual Medicine, 12(3), 783-795. https://doi.org/10.1111/jsm.12819.

Keshavan, M. S., \& Kaneko, Y. (2013). Secondary psychoses: an update. World Psychiatry, 12(1), 4-15. https://doi.org/10.1002/wps.20001.

Kruger, T. H., \& Schiffer, B. (2011). Neurocognitive and personality factors in homo- and heterosexual pedophiles and controls. The Journal of Sexual Medicine, 8(6), 1650-1659. https://doi.org/10. 1111/j.1743-6109.2009.01564.x.

Laird, A. R., Fox, P. M., Price, C. J., Glahn, D. C., Uecker, A. M., \& Lancaster, J. L. (2005). ALE meta-analysis: controlling the false discovery rate and performing statistical contrasts. Human Brain Mapping, 25, 155-164.

Laird, A. R., Robinson, J. L., McMillan, K. M., Tordesillas-Gutiérrez, D., Moran, S. T., Gonzales, S. M., \& Lancaster, J. L. (2010). Comparison of the disparity between Talairach and MNI coordinates in functional neuroimaging data: validation of the Lancaster transform. NeuroImage, 51(2), 677-683.

Lancaster, J. L., Tordesillas-Gutiérrez, D., Martinez, M., Salinas, F., Evans, A., Zilles, K., \& Fox, P. T. (2007). Bias between MNI and Talairach coordinates analyzed using the ICBM-152 brain template. Human Brain Mapping, 28(11), 1194-1205.

Lesniak, R., Szymusik, A., \& Chrzanowski, R. (1972). Case report: Multidirectional disorders of sexual drive in a case of brain tumour. Forensic Science, 1(3), 333-338.

Massau, C., Kargel, C., Weiss, S., Walter, M., Ponseti, J., Krueger, H., \& Schiffer, T. (2017). Neural correlates of moral judgment in pedophilia. Social Cognitive and Affective Neuroscience, 12(9), 1490 1499. https://doi.org/10.1093/scan/nsx077.

McAllister, T. W. (2008). Neurobehavioral sequelae of traumatic brain injury: evaluation and management. World Psychiatry, 7(1), 3-10. https://doi.org/10.1002/j.2051-5545.2008.tb00139.x.

McGorry, P., Keshavan, M., Goldstone, S., Amminger, P., Allott, K., Berk, M.,.. . Hickie, I. (2014). Biomarkers and clinical staging in psychiatry. World Psychiatry, 13(3), 211-223. https://doi.org/10. 1002/wps.20144.

Mendez, M., \& Shapira, J. S. (2011). Pedophilic behavior from brain disease. The Journal of Sexual Medicine, 8(4), 1092-1100. https:// doi.org/10.1111/j.1743-6109.2010.02172.x.

Mendez, M. F. (2010). The unique predisposition to criminal violations in frontotemporal dementia. The Journal of the American Academy of Psychiatry and the Law, 38(3), 318-323.

Mendez, M. F., Chow, T., Ringman, J., Twitchell, G., \& Hinkin, C. H. (2000). Pedophilia and temporal lobe disturbances. The Journal of Neuropsychiatry and Clinical Neurosciences, 12(1), 71-76. https:// doi.org/10.1176/jnp.12.1.71. 
Miller, B. L., Cummings, J. L., McIntyre, H., Ebers, G., \& Grode, M. (1986). Hypersexuality or altered sexual preference following brain injury. Journal of Neurology, Neurosurgery, and Psychiatry, 49(8), 867-873. https://doi.org/10.1136/jnnp.49.8.867.

Moher, D., Liberati, A., Tetzlaff, J., Altman, D. G., \& Group, P. (2009). Preferred reporting items for systematic reviews and meta-analyses: the PRISMA statement. BMJ, 339, b2535. https://doi.org/10.1136/ bmj.b2535.

Mohnke, S., Muller, S., Amelung, T., Kruger, T. H., Ponseti, J., Schiffer, B., \& Walter, H. (2014). Brain alterations in paedophilia: a critical review. Progress in Neurobiology, 122, 1-23. https://doi.org/10. 1016/j.pneurobio.2014.07.005.

Müller, V. I., Cieslik, E. C., Laird, A. R., Fox, P. T., Radua, J., MataixCols, D., \& Eickhoff, S. B. (2018). Ten simple rules for neuroimaging meta-analysis. Neuroscience Biobehavioral Reviews, 84, $151-161$.

Plachti, A., Eickhoff, S. B., Hoffstaedter, F., Patil, K. R., Laird, A. R., Fox, P. T., \& Genon, S. (2019). Multimodal parcellations and extensive behavioral profiling tackling the hippocampus gradient. Cerebral Cortex, 29(11), 4595-4612. https://doi.org/10.1093/ cercor/bhy336.

Poeppl, T. B., Nitschke, J., Dombert, B., Santtila, P., Greenlee, M. W., Osterheider, M., \& Mokros, A. (2011). Functional cortical and subcortical abnormalities in pedophilia: a combined study using a choice reaction time task and fMRI. The Journal of Sexual Medicine, 8(6), 1660-1674. https://doi.org/10.1111/j.1743-6109. 2011.02248.x.

Poeppl, T. B., Nitschke, J., Santtila, P., Schecklmann, M., Langguth, B., Greenlee, M. W., \& Mokros, A. (2013). Association between brain structure and phenotypic characteristics in pedophilia. Journal of Psychiatric Research, 47(5), 678-685. https://doi.org/10.1016/j. jpsychires.2013.01.003.

Ponseti, J., Bruhn, D., Nolting, J., Gerwinn, H., Pohl, A., Stirn, A., \& Kruger, T. H. C. (2017). Decoding pedophilia: increased anterior insula response to infant animal pictures. Frontiers in Human Neuroscience, 11, 645. https://doi.org/10.3389/fnhum.2017.00645.

Ponseti, J., Granert, O., Jansen, O., Wolff, S., Beier, K., Neutze, J., \& Bosinski, H. (2012). Assessment of pedophilia using hemodynamic brain response to sexual stimuli. Archives of General Psychiatry, 69(2), 187-194. https://doi.org/10.1001/archgenpsychiatry.2011. 130.

Rainero, I., Rubino, E., Negro, E., Gallone, S., Galimberti, D., Gentile, S., \& Pinessi, L. (2011). Heterosexual pedophilia in a frontotemporal dementia patient with a mutation in the progranulin gene. Biological Psychiatry, 70(9), e43-e44. https://doi.org/10.1016/j.biopsych. 2011.06.015.

Raymond, N. C., Coleman, E., Ohlerking, F., Christenson, G. A., \& Miner, M. (1999). Psychiatric comorbidity in pedophilic sex offenders. The American Journal of Psychiatry, 156(5), 786-788. https://doi.org/10.1176/ajp.156.5.786.

Regestein, Q. R., \& Reich, P. (1978). Pedophilia occurring after onset of cognitive impairment. The Journal of Nervous and Mental Disease, 166(11), 794-798.

Regier, D. A., Kuhl, E. A., \& Kupfer, D. J. (2013). The DSM-5: Classification and criteria changes. World Psychiatry, 12(2), 9298. https://doi.org/10.1002/wps.20050.

Rorden, C., \& Brett, M. (2000). Stereotaxic display of brain lesions. Behavioural Neurology, 12(4), 191-200. https://doi.org/10.1155/ 2000/421719.

Rorden, C., Fridriksson, J., \& Karnath, H. O. (2009). An evaluation of traditional and novel tools for lesion behavior mapping. Neuroimage, 44(4), 1355-1362. https://doi.org/10.1016/j. neuroimage.2008.09.031.

Sartori, G., Scarpazza, C., Codognotto, S., \& Pietrini, P. (2016). An unusual case of acquired pedophilic behavior following compression of orbitofrontal cortex and hypothalamus by a Clivus Chordoma. Journal of Neurology, 263(7), 1454-1455. https://doi. org/10.1007/s00415-016-8143-y.

Sartorius, A., Ruf, M., Kief, C., Demirakca, T., Bailer, J., Ende, G., \& Dressing, H. (2008). Abnormal amygdala activation profile in pedophilia. European Archives of Psychiatry and Clinical Neuroscience, 258(5), 271-277. https://doi.org/10.1007/s00406008-0782-2.

Scarpazza, C., Pellegrini, S., Pietrini, P., \& Sartori, G. (2018). The role of neuroscience in the evaluation of mental insanity: on the controversies in Italy. Neuroethics, 11(1), 83-95.

Scarpazza, C., Pennati, A., \& Sartori, G. (2018). Mental insanity assessment of pedophilia: the importance of the trans-disciplinary approach. reflections on two cases. Frontiers in Neuroscience, 12, 335. https://doi.org/10.3389/fnins.2018.00335.

Scarpazza, C., Signori, A., Prosperini, L., Sormani, M. P., Cosottini, M., Capra, R., \& Italian, P. M. L. G. (2019). Early diagnosis of progressive multifocal leucoencephalopathy: longitudinal lesion evolution. Journal of Neurology, Neurosurgery, and Psychiatry, 90(3), 261267. https://doi.org/10.1136/jnnp-2018-319208.

Schiffer, B., Amelung, T., Pohl, A., Kaergel, C., Tenbergen, G., Gerwinn, H., \& Walter, H. (2017). Gray matter anomalies in pedophiles with and without a history of child sexual offending. Translational Psychiatry, 7(5), e1129. https://doi.org/10.1038/tp.2017.96.

Schiffer, B., Krueger, T., Paul, T., de Greiff, A., Forsting, M., Leygraf, N., \& Gizewski, E. (2008). Brain response to visual sexual stimuli in homosexual pedophiles. Journal of Psychiatry \& Neuroscience, 33(1), 23-33.

Schiffer, B., Paul, T., Gizewski, E., Forsting, M., Leygraf, N., Schedlowski, M., \& Kruger, T. H. (2008). Functional brain correlates of heterosexual paedophilia. Neuroimage, 41(1), 80-91. https://doi.org/10.1016/j.neuroimage.2008.02.008.

Schiffer, B., Peschel, T., Paul, T., Gizewski, E., Forsting, M., Leygraf, N., \& Krueger, T. H. (2007). Structural brain abnormalities in the frontostriatal system and cerebellum in pedophilia. Journal of Psychiatric Research, 41(9), 753-762. https://doi.org/10.1016/j. jpsychires.2006.06.003.

Schiltz, K., Witzel, J., Northoff, G., Zierhut, K., Gubka, U., Fellmann, H., \& Bogerts, B. (2007). Brain pathology in pedophilic offenders: evidence of volume reduction in the right amygdala and related diencephalic structures. Archives of General Psychiatry, 64(6), 737-746. https://doi.org/10.1001/archpsyc.64.6.737.

Tenbergen, G., Wittfoth, M., Frieling, H., Ponseti, J., Walter, M., Walter, H., \& Kruger, T. H. (2015). The neurobiology and psychology of pedophilia: recent advances and challenges. Frontiers in Human Neuroscience, 9, 344. https://doi.org/10.3389/fnhum.2015.00344.

Turkeltaub, P. E., Eden, G. F., Jones, K. M., \& Zeffiro, T. A. (2002). Meta-analysis of the functional neuroanatomy of single-word reading: method and validation. NeuroImage, 16, 765-780.

Turkeltaub, P. E., Eickhoff, S. B., Laird, A. R., Fox, M., Wiener, M., \& Fox, P. (2012). Minimizing within-experiment and within-group effects in Activation Likelihood Estimation meta-analyses. Human Brain Mapping, 33(1), 1-13.

von Krafft-Ebing, B. (1897). Trattato di Psicopatologia Forense. Fratelli Bocca, Editori (Torino), 215.

Walter, M., Witzel, J., Wiebking, C., Gubka, U., Rotte, M., Schiltz, K., \& Northoff, G. (2007). Pedophilia is linked to reduced activation in hypothalamus and lateral prefrontal cortex during visual erotic stimulation. Biological Psychiatry, 62(6), 698-701. https://doi.org/10. 1016/j.biopsych.2006.10.018.

Publisher's note Springer Nature remains neutral with regard to jurisdictional claims in published maps and institutional affiliations. 